\title{
Decomposition of Earnings-to-Price (E/P) Effect
}

\author{
Walid Saleh (Corresponding author) \\ Associate Professor of Corporate Finance, Arab Open University, Jordan Branch \\ Department of Business, P.O.Box 1339, Amman 11953, Jordan \\ Tel. 962-6-630-630 E-mail:w_saleh@aou.edu.jo
}

Ayman Bitar

Assistant Professor of Financial Management

Petra University/Department of Banking \& Financing sciences

P.O.Box 961334 Amman 11196, Jordan

Tel: 962-77-742-0662Ｅ-mail: akbitar@yahoo.com

Received: April 27, 2011

doi:10.5539/ijef.v4n1p229
Accepted: July 15, $2011 \quad$ Published: January 1, 2012

URL: http://dx.doi.org/10.5539/ijef.v4n1p229

\begin{abstract}
Saleh (2007) employed the Fama and French (1993) three-factor model to investigate the ability of earnings-to-price (E/P), amongst other measures, to explain the cross-sectional stock returns over the period 1980-2000. Inconsistent with previous research, Saleh concluded that the loading of SMB and HML factors is not significant and, thus, he tried to explain these findings by using a multi-factor model.

This paper aims to expand Saleh's (2007) work and thus seeks to explore the earnings-to-price (E/P) performance by decomposing the E/P effect into two components; financial effect and operational effect. The results confirm that SMB and HML factors captured some variation in stock returns that is not captured by the market return.
\end{abstract}

Keywords: Fama and French (1993) three-factor model, Earnings-to-price, CAPM, Contrarian strategies

\section{Introduction}

Considerable research shows that earnings-to-price predicts stock returns (e.g. Basu, 1977, William and Morse, 1978, Reinganum, 1981, Cook and Rozeff, 1984, Levis, 1989, Jaffe et al. 1989 Lakonishok et al. 1994, Dreman, 1998, amongst others). Traditionally, the $\mathrm{P} / \mathrm{E}$ ratio is used as a measure of stock price relative to its earnings. Thus, the $\mathrm{P} / \mathrm{E}$ ratio provides a measure of valuation as a higher $\mathrm{P} / \mathrm{E}$ ratio would mean that investors are willing to pay more for company earnings compared to stocks with lower $\mathrm{P} / \mathrm{E}$ ratios.

William and Morse (1978) examined the behavior of P/E ratios and explored the ability of earnings growth and risk to explain $\mathrm{P} / \mathrm{E}$ ratio differences across stocks. They found that earnings growth and risk appear to explain little of $\mathrm{P} / \mathrm{E}$ ratio differences. Overall, two competing schools were introduced to explain the difference in returns between "value" and "growth" stocks (Note 1). For example, Lakonishok et al. (1994) argued in favor of mispricing explanation in which they found that the difference in expected future growth rates between value and growth stocks were overestimated by investors. However, Fama and French (1993, 1996, and 1998) argued in favor of risk explanation in which they found that a three-factor model (market return, size effect, and book-to-market effect) can explain the difference in returns between value and growth stocks. More recently, Penman and Reggiani (2010) documented that earnings yield and book-to-market combine to predict equity returns in a way that is consistent with the rational pricing of risk. Further, Dubinsky and Johannes (2006) concluded that investors buy earnings and the $\mathrm{E} / \mathrm{P}$ ratio prices the risk in expected earnings.

Anderson and Brooks (2005) provided evidence suggesting that earnings over several previous years hold information useful in predicting subsequent returns. In a following effort, Anderson and Brooks (2005b) decomposed the P/E effect into four effects; year effect, sector effect, size effect, and idiosyncratic effect (Note 2). They found that such an approach widens the gab in annual returns between value and growth deciles by $8 \%$.

Jiang and Lee (2009) investigated the prediction of excess returns and fundamentals by financial ratios (e.g. earnings-to-price ratio, book-to-market ratio, and dividend-to-price ratio) by splitting financial ratios into two 
components: cyclical components and stochastic trend components. They found that the cyclical components predict increases in future stock returns, whilst the stochastic trend components predict declines in future stock returns. Pietrovite (2009) confirmed that managers use the information contained in the $\mathrm{P} / \mathrm{E}$ ratios to make investment decisions.

Saleh (2007) examined the performance of the value-growth strategies based on two measures; earnings-to-price and divided-to-price. He used the CAPM and the Fama-French three factor model to investigate the ability of these two measures to explain the cross-sectional stock returns. Inconsistent with previous research Saleh provided evidence suggesting that the SMB and HML factors are not significant when he sorted stocks based on E/P and D/P ratios. He tried to explain such findings by using a multi-factor model; Fama-French three-factor model augmented with liquidity, leverage, volatility, and winner-loser effects.

This paper aims to extend Saleh's (2007) work by shedding further lights on the performance of E/P stocks by decomposing the E/P effect into two components; financial components and operational components. Consistent with previous research, the paper concludes that the SMB and HML factors captured some variation in stock returns that is not captured by the market return.

The remainder of this paper is organized as follows. Section 2 describes the empirical design and data, Section 3 presents the results and finally Section 4 concludes.

\section{Data and Research Methodology}

The empirical analysis of this paper uses monthly returns and annual accounting data over the period 1980-2002. The sample data is constructed from all nonfinancial Jordanian companies. The paper uses 3-month Treasury bill rates and monthly returns on ASE value-weighted index as a proxy for risk free rate and market returns, respectively. To be included in the sample for year $\mathrm{t}$, companies must have data for E/P ratio recorded in December of year $\mathrm{t}-1$ and at least one return observation for the 12 months from April of year $\mathrm{t}$ to March of year $\mathrm{t}+1$.

Following Fama and French (1998) and Saleh (2007), companies with negative E/P ratio are excluded. The proceeds from a stock that de-lists during the holding period are distributed among other stocks in the portfolio according to their value-weighted.

Saleh (2007) investigated the performance of E/P stocks using data from Amman Stock Exchange and found that the loading of SMB and HML factors is not significant, which is not consistent with previous research. He tried to explain this result by using a multi-factor model; the Fama and French (1993) three-factor model augmented by liquidity effect, leverage effect, winner-loser effect, and stock return volatility effect. The multi-factor model does a better job in explaining the variation in stock returns.

This paper seeks to shed further lights on the performance of high E/P stocks against low E/P stocks by splitting the E/P effect into two components: the financial effect and the operational effect. The paper uses the NI-EBIT/P to reflect the financial effect whilst uses the EBIT/P ratio to reflect the operational effect, where; NI is the net income after tax, EBIT is earnings before interest and tax, and $\mathrm{P}$ is the market value of equity.

The paper conducts a portfolio analysis approach to investigate the performance of high E/P stocks against low E/P stocks. For each year, stocks are sorted based on their NI-EBIT/P and EBIT/P ratios. Portfolios of stocks are formed annually in April. Thus, for each year, stocks are sorted in an ascending order into three portfolios based on their NI-EBIT/P and EBIT/P values. Higher portfolio is assigned to "value" portfolio, whilst lower portfolio is assigned to a "growth" portfolio.

The paper allows for a four-month lag between the measurements of accounting and return data to ensure that the accounting data is available to investors before returns are recorded.

Then, for each portfolio, the paper computes returns for one-year period to five-year-period. Also, the paper calculates the simple average over the five-year period and the average cumulative five-year returns with annual compounding.

Next, the paper monitors the performance of high NI-EBIT/P and EBIT/P stocks against the performance of low NI-EBIT/P and EBIT/P stocks. Moreover, the paper examines the difference in returns between high and low NI-EBIT/P and EBIT/P stocks by employing the CAPM and the Fama and French (1993) three-factor model as follows:

$$
\begin{aligned}
& R_{p}-R_{f}=a_{i}+\beta\left(R_{m}-R_{f}\right)+e_{i, t} \\
& R p-R_{f}=a_{i}+\beta\left(R_{m}-R_{f}\right)+s_{i} S M B+h_{i} H M L+e_{i, t}
\end{aligned}
$$

Where, $R_{p}-R_{f}$ is the excess returns for individual portfolios, $R_{m}$ is the monthly return of the ASE 
value-weighted index, $R_{f}$ is the monthly 3 -month Treasury bill rate. SMB (small minus big) is the difference, each month, between the average of the returns on the three small-stock portfolios $(\mathrm{S} / \mathrm{L}, \mathrm{S} / \mathrm{M}$, and $\mathrm{S} / \mathrm{H})$ and the average of the returns on the three big-stock portfolios $(\mathrm{B} / \mathrm{L}, \mathrm{B} / \mathrm{M}$, and $\mathrm{B} / \mathrm{H})$. HML is the difference, each month, between the average of the returns on the two high-book-to-market portfolios $(\mathrm{S} / \mathrm{H}$ and $\mathrm{B} / \mathrm{H})$ and the average of the returns on the two low-book-to-market portfolios (S/L and B/L). Following Fama and French (1993) the mimicking portfolios for the size (SMB) and book-to-market (HML) factors are constructed as follows. At the end of April of each year $t$ stocks are allocated to two groups (big and small) based on whether their market value is above or below the median of the market. Moreover, stocks are allocated in an independent sort to three book-to-market groups (high, medium, and low) based on the breakpoints for the top 30 percent, middle 40 percent, and bottom 30 percent of the book-to-market values.

\section{Empirical Results}

\subsection{Summary Descriptive Statistics}

Descriptive statistics of the test variables are presented in Table 1 in which it shows mean and standard deviation of the test variables. The P-values of the test variables are significant; $0.005,0.008$, and 0.012 for market return, size effect, and book-to-market effect, respectively.

\subsection{Value-Weighted Returns}

Panels A and B of Table 2 present the value weighted returns for portfolios formed based on EBIT/P and NI-EBIT/P stocks, respectively. Panel A of Table 2 shows that on average high EBIT/P stocks earn higher returns than low EBIT/P stocks; the difference in returns between high EBIT/P stocks and low EBIT/P stocks is 0.199 and 0.108 over the three-year and five-year period, respectively.

Panel B of Table 2 concludes that high NI-EBIT/P stocks underperform low NI-EBIT/P stocks with an average of 0.015 and 0.067 over the three-year and five-year period, respectively.

\subsection{The CAPM and the Fama-French Three-Factor Model}

In this sub-section the paper employs the CAPM and the Fama and French (1993) three-factor model to test whether they can explain the difference in returns between the highest NI-EBIT/P and EBIT/P stocks and the lowest NI-EBIT/P and EBIT/P stocks. Thus, the paper tests whether the intercept in each of the regressions is equal to zero using a conventional t-statistic.

Panels A and B of Table 3 (4) report the results of the CAPM (Fama-French three-factor model) for portfolios formed based on NI-EBIT/P and EBIT/P stocks, respectively. The results from Panels A and B of Table 3 show that the values of the intercept coefficient for the arbitrage portfolio (VMG) are not significant. The beta coefficient values for the VMG portfolios are 0.158 and -0.077 with t-statistics of 1.112 and -0.527 , respectively. This result suggests that the difference in returns between high and low NI-EBIT/P and EBIT/P stocks is not attributed to changes in risk as measured by the CAPM betas. The values of the adjusted $R^{2}$ are 0.001 and 0.001 , respectively. This result suggests that the CAPM does not fully explain the difference in returns between high NI-EBIT/P and EBIT/P stocks and low NI-EBIT/P and EBIT/P stocks. The above result is consistent with previous studies in emerging markets. For instance, Cheung et al. (1993) found that the risk-return relationship in Korean and Taiwanese markets is weak. Further, Huang (1997) found that the risk-return relationship is negative for Taiwanese market.

The results from Panels A and B of Table 4 show that the Fama-French's three-factor model captures most of the common variation in stock returns. The adjusted $R^{2}$ values of the three-factor model is higher than those of the CAPM; the adjusted $R^{2}$ values are 0.759 and 0.833 (Table 4, Panels A and B, respectively) for the VMG portfolios in the Fama-French three-factor model, whilst the corresponding figures for the CAPM are 0.001 and 0.001 (Table 3, Panels A and B, respectively).

The loading of SMB factor for the VMG portfolio is significant. For instance, Panel A of Table 4 shows that the value of SMB factor for the VMG portfolio is 0.192 with a t-statistic of 4.179, when the paper formed the portfolios based on NI-EBIT/P ratio. However, the value of the SMB factor is -0.260 with a t-statistic of -6.640 , when the paper formed portfolios based on EBIT/P ratio. This is an interesting result. Recall that Saleh (2007) found that the loading of SMB factor is not significant when he formed portfolios based on E/P values. He tried to explain such result by using a multi-factor model including several factors such as liquidity effect, winner-loser effect, volatility effect, and leverage effect. The result of this paper suggests that the positive size effect (SMB factor) of NI-EBIT/P is cancelled by the negative size effect of EBIT/P, thus, the overall size effect of $\mathrm{E} / \mathrm{P}$ is not significant.

The loading of HML factor for the VMG portfolios is significant and positive; 1.034 and 1.087 with t-statistics of 
24.491 and 29.640, respectively. This result is consistent with previous research findings (e.g. Fama and French, 1998, amongst others).

To sum up, the above results show that SMB and HML factors explain some variation in stock returns that is not captured by the market return.

\section{Summary and Conclusion}

Saleh (2007) investigated the performance of high E/P stocks against low E/P stocks using data from Amman Stock Exchange. He provided evidence suggesting that the loading of SMB and HML factors is not significant which is not consistent with previous research findings. Saleh (2007) employed a multi-factor model; the Fama-French three-factor model augmented with liquidity effect, winner-loser effect, volatility effect and leverage effect to explain such findings.

The main aim of this paper was to shed further lights on the performance of high E/P stocks against low E/P stocks. Therefore, the paper decomposes the E/P effect into two components: financial earnings effect and operational earnings effect. Overall, consistent with previous research this paper provides evidence suggesting that the SMB and HML factors captured some variation in stock returns that is not captured by the market returns.

\section{References}

Anderson K., \& C. Brooks (2005). The Long-Term P/E Ratio. Working paper, ISMA Centre, University of Reading and City University, London.

Anderson K. and C. Brooks (2005b). Decomposing the P/E Ratio. Working paper, ISMA Centre, University of Reading and City University, London.

Basu, S. (1977). The Investment Performance of Common Stocks in Relation to their Price-Earnings Ratios. Journal of Finance, Vol. 32, No. 3, PP. 663-682.

Cai, J. (1997). Glamour and Value Strategies On The Tokyo Stock Exchange. Journal of Business Finance and Accounting, Vol.24, No. 9\&10, PP. 1291-1310.

Cheung, Y.L., K.A. Wong, \& Y.K. Ho. (1993). The pricing of risky assets in two emerging Asian markets - Korea and Taiwan. Applied Financial Economics, Vol. 3, PP. 315-324.

Cook, T., \& M. Rozeff. (1984). Size and Earnings/Price Ratio Anomalies: One Effect or Two?. Journal of Financial and Quantitative Analysis, Vol. 19, No. 4, PP. 449-466.

Dreman, D.N. (1998). Contrarian Investment Strategies: The Next Generation, New York, Simon and Schuster.

Dubinsky, A., \& M. Johannes. (2006). Earnings announcements and equity options. Working paper, Columbia Business School.

Fama, E., \& K. French. (1993). Common Risk Factors In The Returns On Stocks and Bonds. Journal of Financial Economics, Vol. 33, PP. 3-56.

Fama, E., \& K. French. (1996). Multifactor Explanations of Assets Pricing Anomalies. The Journal of Finance, Vol. 51, No.1, PP. 55-84.

Fama, E., \& K. French. (1998). Value Versus Growth: The International Evidence. The Journal of Finance, Vol.53, PP.1975-1998.

Huang, Y.S. (1997). An empirical test of the risk-return relationship on the Taiwan Stock Exchange, Applied Financial Economics, Vol. 7, PP. 229-239.

Jaffe, J., D. Keim, \& R. Westerfield. (1989). Earnings Yields, Market Values, and Stock Returns. Journal of Finance, Vol. 44, No. 1, PP. 135-148.

Jiang, X., \& B. S. Lee. (2009). Do Decomposed Financial Ratios Predict Stock Returns and Fundamentals Better?. Working paper, Florida International University and Florida State University.

Lakonishok, J., A. Shleifer, \& R.W. Vishny (1994). Contrarian Investment, Expectation, and Risk. The Journal of Finance, Vol. 49, No.5, PP. 1541-1578.

Levis, M. (1989). Stock Market Anomalies. Journal of Banking and Finance, Vol. 13, PP. 675-696.

Penman, S., \& F. Reggiani. (2010). Returns to Buying Earnings and Book Value: Accounting for Growth and Risk. Working paper, Columbia University and Bocconi University.

Pietrrovito, F. (2009). Investment decisions, price-earnings ratios and finance: Evidence from firm level data. Working paper, University degli Studi del Molise. 
Saleh, W. (2007). Earnings-to-Price, Dividend-to-Price, Firm Growth and Stock Returns. Jordan Journal of Business Administration, Vol. 3, No. 1, PP. 85-105.

Reinganum, M. (1981). Misspecification of Capital Asset Pricing: Empirical Anomalies Based on Earnings' Yield and Market Values. Journal of Financial Economics, Vol. 9, No. 1, PP. 19-46.

White, H. (1980). A Heteroskedasticity-Consistent Covariance Matrix Estimator and a Direct Test for Heteroskedasticity. Econometrica, Vol. 48, 1980, pp. 817-838. http://dx.doi.org/10.2307/1912934

William, B., \& Morse, D. (1978). What Determines Price-Earnings Ratios. Financial Analysts Journal, Vol. 34, No. 4, PP. 65-76.

\section{Notes}

Note 1. "Value" stocks refer to those stocks that have low price relative to some measures of their fundamental value, whereas "growth" stocks refer to those stocks that have high price relative to some measure of their fundamental value.

Note 2. Idiosyncratic effect refers to companies in the same year, operating in the same sector and similar sizes nevertheless always have different $\mathrm{P} / \mathrm{E}$ 's.

Table 1. Summary Descriptive Statistics of Models Factors

\begin{tabular}{|c|c|c|c|}
\hline & XMR & SMB & HML \\
\hline Mean & -0.0001 & 0.0019 & -0.0201 \\
\hline Std dev & 0.0356 & 0.0578 & 0.0822 \\
\hline P-value & 0.005 & 0.008 & 0.012 \\
\hline
\end{tabular}

The sample includes all nonfinancial Jordanian firms listed in Amman Stock Exchange over the 1980-2002 period. XMR is the excess market return, SMB (small minus big) is the monthly difference between the average of the returns on the three small-stock portfolios ( $\mathrm{S} / \mathrm{L}, \mathrm{S} / \mathrm{M}$, and $\mathrm{S} / \mathrm{H})$ and the average of the returns on the three big-stock portfolios $(\mathrm{B} / \mathrm{L}, \mathrm{B} / \mathrm{M}$, and $\mathrm{B} / \mathrm{H})$. HML is the monthly difference between the average of the returns of the two high book-to-market portfolios $(\mathrm{S} / \mathrm{H}$ and $\mathrm{B} / \mathrm{H})$ and the average of the returns on the two low-book-to-market portfolios $(\mathrm{S} / \mathrm{L}$ and $\mathrm{B} / \mathrm{L}$ ). P-value is calculated with standard errors using White (1980).

Table 2. Value-Weighted Returns for Portfolios

\begin{tabular}{|c|c|c|c|c|}
\hline \multicolumn{5}{|l|}{ Panel A: EBIT/P } \\
\hline & Low & Medium & High & High - low \\
\hline R1 & 0.042 & 0.114 & 0.184 & 0.142 \\
\hline $\mathbf{R 2}$ & 0.164 & 0.139 & 0.233 & 0.069 \\
\hline $\mathbf{R 3}$ & 0.085 & 0.150 & 0.096 & 0.011 \\
\hline R4 & 0.138 & 0.133 & 0.047 & -0.091 \\
\hline R5 & 0.174 & 0.059 & 0.090 & -0.083 \\
\hline AR CR3 & 0.315 & 0.362 & 0.514 & 0.199 \\
\hline AR CR5 & 0.685 & 0.747 & 0.793 & 0.108 \\
\hline \multicolumn{5}{|l|}{ Panel B: (NI-EIBT) /P } \\
\hline & Low & Medium & High & High - low \\
\hline R1 & 0.085 & 0.195 & 0.069 & -0.017 \\
\hline $\mathbf{R 2}$ & 0.197 & 0.171 & 0.163 & -0.034 \\
\hline $\mathbf{R 3}$ & 0.107 & 0.148 & 0.079 & -0.028 \\
\hline R4 & 0.130 & 0.091 & 0.052 & -0.078 \\
\hline R5 & 0.053 & 0.165 & 0.094 & 0.041 \\
\hline AR CR3 & 0.334 & 0.583 & 0.319 & -0.015 \\
\hline AR CR5 & 0.574 & 1.031 & 0.508 & -0.067 \\
\hline
\end{tabular}

Note: Table-2 values represent mean one-to-five-year buy and hold returns for portfolios formed in April each year, based on EBIT/P and NIEBIT/P values, respectively. The sample period is from 1980-2002. AR5 is the average return for R1 to R5. CR3 and CR5 are the three-year and five-year cumulative returns. 
Table 3. The CAPM Model

Panel A: Value-Weighted Returns for One Year for Portfolios formed based on NI-EBIT/P

\begin{tabular}{|c|c|c|c|c|}
\hline & Low & Medium & High & (High- Low) \\
\hline $\boldsymbol{a}$ & 0.001 & 0.008 & 0.000 & -0.006 \\
\hline $\mathrm{t}(\mathrm{a})$ & 0.399 & 1.523 & 0.014 & -1.239 \\
\hline $\boldsymbol{\beta}$ & 0.827 & 1.294 & 0.978 & 0.158 \\
\hline $\mathrm{t}(\beta)$ & 9.206 & 8.762 & 6.984 & 1.112 \\
\hline $\mathbf{A d j} \mathbf{R}^{2}$ & 0.305 & 0.284 & 0.200 & 0.001 \\
\hline
\end{tabular}

Panel B: Value-Weighted Returns for One Year for Portfolios formed based on EBIT/P

\begin{tabular}{|c|c|c|c|c|}
\hline & Low & Medium & High & (High- Low) \\
\hline $\boldsymbol{a}$ & -0.003 & 0.003 & 0.008 & 0.006 \\
\hline $\mathrm{t}(\mathrm{a})$ & -0.466 & 0.657 & 2.279 & 1.096 \\
\hline $\boldsymbol{\beta}$ & 1.078 & 1.037 & 0.993 & -0.077 \\
\hline $\mathrm{t}(\beta)$ & 6.999 & 7.255 & 10.060 & -0.527 \\
\hline Adj $\mathbf{R}^{2}$ & 0.201 & 0.213 & 0.344 & 0.001 \\
\hline
\end{tabular}

Note that

$$
R_{j, t}-R_{f, t}=a_{j}+\beta_{j}\left(R_{m, t}-R_{f, t}\right)+e_{j, t}
$$

Where, $R_{p}-R_{f}$ is the excess returns for individual portfolios ${ }^{2}, R_{m}$ is the monthly return of the ASE value-weighted index, $R_{f}$ is the monthly 3-month Treasury bill rate.

Table 4. The Fama-French three-factor Model

\begin{tabular}{|c|c|c|c|c|}
\hline \multicolumn{5}{|c|}{ Panel A: Value-Weighted Returns for One Year for Portfolios formed based on NI-EBIT/P } \\
\hline & Low & Medium & High & (High- Low) \\
\hline$a$ & 0.000 & 0.007 & 0.001 & -0.004 \\
\hline $\mathrm{t}(\mathrm{a})$ & 0.015 & 1.515 & 0.289 & -1.514 \\
\hline $\boldsymbol{\beta}$ & 0.851 & 1.254 & 0.871 & 0.027 \\
\hline $\mathrm{t}(\beta)$ & 11.267 & 9.353 & 8.324 & 0.391 \\
\hline$S M B$ & 0.261 & 0.589 & 0.455 & 0.192 \\
\hline $\mathrm{t}(\mathrm{s})$ & 5.202 & 6.627 & 6.458 & 4.179 \\
\hline$H M L$ & -0.300 & 0.120 & 0.732 & 1.034 \\
\hline $\mathrm{t}(\mathrm{h})$ & -6.514 & 1.464 & 11.460 & 24.491 \\
\hline $\operatorname{Adj} \mathbf{R}^{2}$ & 0.512 & 0.414 & 0.556 & 0.759 \\
\hline \multicolumn{5}{|c|}{ Panel B: Value-Weighted Returns for One Year for Portfolios formed based on EBIT/P } \\
\hline & Low & Medium & High & P4 (High- Low) \\
\hline$a$ & 0.005 & 0.001 & 0.002 & -0.008 \\
\hline $\mathrm{t}(\mathrm{a})$ & 1.201 & 0.248 & 0.581 & -3.466 \\
\hline$\beta$ & 0.966 & 0.999 & 0.986 & 0.028 \\
\hline $\mathrm{t}(\beta)$ & 9.376 & 7.343 & 11.897 & 0.464 \\
\hline$S M B$ & 0.614 & 0.426 & 0.357 & -0.260 \\
\hline $\mathrm{t}(\mathrm{s})$ & 9.103 & 4.784 & 6.586 & -6.640 \\
\hline$H M L$ & -0.744 & 0.009 & 0.342 & 1.087 \\
\hline $\mathrm{t}(\mathrm{h})$ & -11.794 & 0.109 & 6.745 & 29.640 \\
\hline $\operatorname{Adj} R^{2}$ & 0.644 & 0.291 & 0.540 & 0.833 \\
\hline
\end{tabular}

Note that

$$
R p-R_{f}=a_{i}+\beta\left(R_{m}-R_{f}\right)+s_{i} S M B+h_{i} H M L+e_{i, t} \quad \text { (Fama-French) }
$$

Where, $R_{p}-R_{f}$ is the excess returns for individual portfolios ${ }^{2}, R_{m}$ is the monthly return of the ASE value-weighted index, $R_{f}$ is the monthly 3-month Treasury bill rate. SMB (small minus big) is the difference, each month, between the average of the returns on the three small-stock portfolios $(\mathrm{S} / \mathrm{L}, \mathrm{S} / \mathrm{M}$, and $\mathrm{S} / \mathrm{H})$ and the average of the returns on the three big-stock portfolios $(\mathrm{B} / \mathrm{L}, \mathrm{B} / \mathrm{M}$, and $\mathrm{B} / \mathrm{H})$. $\mathrm{HML}$ is the difference, each month, between the average of the returns on the two high-book-to-market portfolios $(\mathrm{S} / \mathrm{H}$ and $\mathrm{B} / \mathrm{H})$ and the average of the returns on the two low-book-to-market portfolios (S/L and B/L). Following Fama and French (1993) the mimicking portfolios for the size (SMB) and book-to-market (HML) factors are constructed as follows. At the end of April of each year $t$ stocks are allocated to two groups (big and small) based on whether their market value is above or below the median of the market. Moreover, stocks are allocated in an independent sort to three book-to-market groups (high, medium, and low) based on the breakpoints for the top 30 percent, middle 40 percent, and bottom 30 percent of the book-to-market values. 